\title{
O PAPEL DA HISTÓRIA NA FORMAÇÃO MORAL DO EDUCANDO SEGUNDO KANT
}

\author{
THE ROLE OF HISTORY IN THE MORAL FORMATION OF EDUCATING SECOND \\ KANT
}

Renata Cristina Lopes Andrade ${ }^{1}$

\begin{abstract}
RESUMO: Considerando a Filosofia e a Pedagogia de Kant, buscaremos expor alguns argumentos e considerações acerca do papel da história na possível formação moral e atuação ética do educando. A formação moral do aluno, via educação, implica, de acordo com o pensamento kantiano, no desenvolvimento da autonomia moral e na realização de ações éticas propriamente ditas. Então colocamos: em Kant, como pode ocorrer, via educação, a formação do ser humano autônomo e ético? Tendo em vista a questão, abordaremos algumas obras do pensamento kantiano, para, nesse momento, buscar esclarecer a função da história no processo de desenvolvimento e formação moral do educando e em sua futura ação ética no mundo. Segundo Kant, qual pode ser o papel da história no trato dos preceitos e ensinamentos morais, na formação e desenvolvimento, na divulgação, no reforço e na realização dos princípios morais na vida e vivências da natureza humana? Eis a ocasião de análise e de avaliação da educação a partir da compreensão dos seus fundamentos.
\end{abstract}

Palavras-chave: Kant. Educação. História. Moralidade. Ética.

\begin{abstract}
Considering the Philosophy and Pedagogy of Kant, we will seek to expose some arguments and considerations about the role of history in the possible moral formation and educating of ethics. The moral education of students via education implies, according to the Kantian, in the development of moral autonomy and conducting themselves ethical actions. Then we put: in Kant, as can occur, through education, the formation of the independent and ethical human? In view of the issue, we discuss some works of Kant's thought, for at that time, seek to clarify the role of history in the development and moral education of the student and his future ethical action in the world. According to Kant, what can be the role of history in dealing with the precepts and moral teaching, formation and development, dissemination, strengthening and realization of moral principles in the life and experiences of human nature? Here is the occasion for analysis and evaluation of education from the understanding of the fundamentals.
\end{abstract}

Keywords: Kant. Education. History. Morality. Ethics.

1 Professora visitante na Universidade Federal de Goiás/ Regional Jataí (UFG). Doutora em Educação pela Universidade Estadual Paulista Júlio de Mesquita Filho (UNESP/ Campus de Marília). 


\title{
1. Sobre a formação moral e a educação kantiana
}

Quando nos aproximamos da pedagogia kantiana e abarcamos os objetivos da educação conforme concebidos pelo filósofo, observamos o desenvolvimento de um trio de estágios - habilidades, prudência e moralidade necessários para o pleno desenvolvimento humano. Desenvolvimento que Kant chamou de Humanidade (o desenvolvimento de sua humanidade), própria de todo ser humano, sem exceção.

Desse modo, a pedagogia de Kant é apresentada, constituída e sustentada enquanto:

10) Mecânico-escolástica: que envolve o desenvolvimento das habilidades, qualidades e capacidades da natureza humana, no que diz respeito, por exemplo, ler e escrever, realizar uma arte, tocar um instrumento. Formando, portanto, um ser humano hábil. No momento da educação mecânico-escolástica está presente - aprimoramento da faculdade de conhecer, proporcionando um conteúdo cognitivo. De acordo com Kant:

\begin{abstract}
A cultura abrange a instrução e vários conhecimentos. A cultura é a criação da habilidade e esta é a posse de uma capacidade condizente com todos os fins que almejamos [...] Algumas formas de habilidade são úteis em todos os casos, por exemplo, o ler e o escrever; outras só são boas em relação a certos fins [...]. A habilidade é de certo modo infinita, graças aos muitos fins (KANT, 1999, p. 25-26, grifo nosso).
\end{abstract}

$\left.2^{\circ}\right)$ Pragmática: refere-se à prudência que, segundo Kant, se apresenta como uma espécie de cultura denominada de civilidade. Oliveira (2004, p. 456) explica que a pessoa prudente, e, portanto, para Kant, civilizada, possui certos refinamentos que a pessoa meramente hábil não possui. No que diz respeito à civilidade, ou seja, a formação pragmática, Kant aponta que as belas artes e as ciências podem ser bastante eficazes para esse desenvolvimento.

[...] por um prazer universalmente comunicável e pelas boas maneiras e refinamento na sociedade, ainda que não façam o homem moralmente melhor, tornam-no porém civilizados, sobrepõem-se em muito à tirania da dependência dos sentidos e 
preparam-no assim para um domínio, no qual só a razão deve mandar (KANT, 1993, p. 274).

30) Moral: por fim, a formação moral diz respeito à ética e ao intrínseco valor das ações humanas, a saber, o valor moral. "Por último vem a formação moral, enquanto é fundada sobre princípios que o homem deve reconhecer" (KANT, 1999, p. 35-36). Com o desígnio de formar moralmente a educação deve:

[...] cuidar da moralização. Na verdade, não basta que o homem seja capaz de toda sorte de fins; convém também que ele consiga a disposição de escolher apenas os bons fins. Bons são aquele fins aprovados necessariamente por todos e que podem ser, ao mesmo tempo, os fins de cada um (KANT, 1999, p. 26, grifo nosso).

No que diz respeito à educação e ao desenvolvimento do educando, o filósofo coloca que não se trata apenas de saber se seríamos mais felizes no estado de barbarismos ou no estado de cultura e civilização, antes, trata-se de uma questão fundamental - "como poderíamos tornar os homens felizes, se não os tornamos morais e sábios?" (KANT, 1999, p. 28).

O caminho para tal desenvolvimento encontramos, principalmente, nas preleções Sobre a Pedagogia (KANT, 1999), embora, também, haja referências nas obras Crítica da razão pura (KANT, 1983), Crítica da razão pratica (KANT, 2003b), Crítica do Juízo (KANT, 1993), Metafísica dos costumes (2003a) e Antropologia de um ponto de vista pragmático (1798).

Para a plena formação do ser humano, ou seja, o desenvolvimento de sua Humanidade, é pressuposto em Kant o desenvolvimento da razão. A razão humana, segundo Kant, é uma faculdade dos princípios - dos princípios teóricos do conhecimento e dos princípios práticos/morais. Da razão humana, enquanto a faculdade dos princípios, se segue a possibilidade do desenvolvimento moral da natureza humana, a formação ou o desenvolvimento de uma faculdade própria de todo e qualquer ser humano.

É importante ressaltar que, de acordo com a pedagogia kantiana, não se trata de aprender regras ou normas morais, não se trata de uma educação que se resume, meramente, moralizante, mediante exortações, de meros conselhos ou de advertências comportamentais, o que se encerraria, precisamente, apenas 
na moralização. Trata-se da formação ou do desenvolvimento, via educação, de uma capacidade própria da natureza humana.

Em Kant, desenvolver/formar moralmente significa atentar-se para uma faculdade e capacidade própria do ser humano: a capacidade prática da sua razão. Uma capacidade da razão capaz de mover a vontade humana, uma faculdade de determinação do querer fazer, do querer agir, de decisão e de escolha. Vale dizer que uma escolha moral implica, nesse contexto, em se dar razões morais para agir.

Uma das alternativas para esse desenvolvimento é a educação, de acordo com Kant: a Arte de educar.

Segundo a compreensão da educação kantiana, o aluno deve ir à escola, não somente para conhecer, mas para desenvolver a capacidade de pensar e agir moralmente, o que forma/desenvolve o autoconhecimento ou a autoderminação moral.

Conforme pondera Bueno:

Talvez possamos dizer que a educação consiste na passagem da inteira dependência de um ser humano, a criança, em relação a outro ser humano, o adulto, até a sua independência em relação a esse. Daí Kant ter como o objetivo da educação o incentivo à prática da autonomia e da autodeterminação (BUENO, 2012, p. 168).

Assim sendo, pensamos que há com a educação, no interior do pensamento de Kant, e conforme concebida por ele, o desenvolvimento, a difusão, o fortalecimento e a possibilidade de efetivação dos princípios morais, o fortalecimento e efetividade da própria moralidade, em resumo, a possibilidade da ação (em geral) do ser humano detentora de valor moral, o que significa a ação ética propriamente dita, ações éticas realizadas no mundo, mediante a formação moral da natureza humana.

Após os esclarecimentos iniciais, vejamos algumas considerações de Kant sobre a História no terceiro estágio para a formação integral do ser humano - o papel da história na formação e desenvolvimento moral do aluno.

\section{O papel da história na formação moral do educando}


Na obra Metafísica dos costumes (2004a) Kant nos fala sobre um Método e sobre uma Técnica para o ensino, no sentido de formação e de envolvimento, da moral.

No que diz respeito ao Método para chamar a atenção do jovem à moralidade, à prática da virtude, ao despertar das próprias forças morais, o filósofo diz que deve ser sistemático e não fragmentado, podendo ocorrer de dois modos: i) o ensino acroamático e ii) o ensino erotemático.

Com o método acroamático todos aqueles a quem se dirige a exposição são apenas ouvintes. Todos, exceto o professor, são somente ouvintes. Segundo Kant, com o método acroamático há, unicamente, a exposição de juízos determinantes, o conteúdo é exposto, regras particulares e empíricas são apreendidas, compreendidas, ou meramente aceitas pelo educando.

Com o método erotemático, por sua vez, o professor pergunta aos seus discípulos o que se quer ensinar, há a reflexão e o desenvolvimento de juízos prévios.

Podemos observar que, com o método erotemático para o desenvolvimento moral e ético, Kant nos ajuda a pensar, por exemplo, acerca da presença da disciplina "Educação Moral e Cívica" nos currículos escolares brasileiros de 1969 a 1993. O Decreto-lei no 869, de 12 de setembro de 1969 (BRASIL, 1969), estabeleceu, em caráter obrigatório, enquanto disciplina escolar e prática educativa, a "Educação Moral e Cívica", em todos os níveis de ensino no Brasil. A disciplina tinha por finalidade fortalecer a unidade nacional e o sentimento de solidariedade humana, o aperfeiçoamento do caráter unido à moral, à família, e à comunidade, bem como o preparo do cidadão, para que o estudante pudesse exercer suas atividades cívicas sustentadas pela moral, patriotismo e o bem comum. No entanto, analisando alguns dos livros didáticos publicados a partir de 1970, há, de forma visível, somente uma utilização do método acroamático. O livro didático, utilizado como parte do material pedagógico da disciplina escolar Educação Moral e Cívica, apresenta-se, enquanto objeto educativo que pertence, ademais, somente a um universo escolar portador do estabelecimento, da definição e da classificação de conhecimentos teóricos. Em Kant, somente o 
conceito não é suficiente para mover o sujeito à ação com valor moral - à ação ética.

O método erotemático é subdividido em duas etapas, a saber, catequético e dialógico.

A exposição é catequética, método catequético de ensino, quando unicamente se interroga a memória do educando, são questionadas e despertadas as suas memórias. A exposição é dialógica, também conhecida como o método Socrático de ensinar, quando o professor pergunta à razão (intelecto) do educando, mediante o ensino dialógico professor e educando alterna perguntas e respostas entre si, pois "se alguém quer perguntar algo à razão de outrem só pode fazê-lo dialogicamente" (KANT, 2004b, p. 128), ou seja, professor e educando se interrogam, e respondem, reciprocamente.

A subdivisão do método erotemático em dialógico e catequético é, também, assinalada por Kant no final do Manual dos cursos de lógica geral (1800). Na presente obra o filósofo define quais seriam os métodos de ensino mais adequados para a elaboração e trato dos conhecimentos, sustentando, no Manual dos cursos de lógica geral - As diversas divisões do método, o método mais adequado de ensino, o método erotemático (Erotematisch), precisamente por exigir a reflexão do educando.

Importa dizer que, no que tange à moralidade, trata-se um conhecimento prático, tem-se em vista o dever-ser, isto é, tudo o que deve necessariamente acontecer do ponto de vista da moralidade. Para o caso de um conhecimento prático, mediante a reflexão, há, segundo Kant, a formação de juízos prévios e não somente o entendimento ou aceitação dos juízos determinantes, afinal: "é peculiar à natureza do homem amar aquilo que ele, pela sua elaboração, converteu em ciência" (KANT, 2004b, 134), o ser humano pode sentir, desse modo, a compreensão e o progresso prático da sua faculdade de julgar.

Já sobre a Técnica para chamar a atenção do jovem aos valores e despertar as suas forças morais:

O meio experimental (técnico) da educação para a virtude é o bom exemplo no próprio mestre (que se comporte de um modo exemplar) e, nos outros, o exemplo admoestador; pois a imitação é, no homem ainda inculto, a primeira determinação da vontade para a aceitação das máximas que, em seguida, ele adota (KANT, 2004b, p. 129). 
Adotar uma máxima, nesse contexto, significa adotar um princípio em função do qual o sujeito quer viver.

Sobre o bom exemplo - a técnica para o desenvolvimento moral do educando - foi, também, observado em Homero, o poeta evoca o exemplo dos heróis famosos e vitoriosos em suas sagas como modelo na apresentação dos valores morais e de ações éticas. Homero apresenta o herói como um modelo para as futuras gerações, uma representação de ser humano honrado, virtuoso e vigoroso. O bom exemplo moral/ético será utilizado, igualmente, na filosofia posterior com Sócrates, que apresenta o modelo ético do bem e na estrutura íntima do pensamento de Platão.

Portanto, vemos na história da filosofia, bem como na história geral, os bons exemplos extraídos da História, conforme apontado em Kant, como a técnica para a formação moral, enquanto um recurso que ajuda na apresentação e na formação dos conceitos, princípio e valores morais.

No que diz respeito à técnica, o pressuposto é que, por meio do bom exemplo histórico, unido com a capacidade do ser humano de reflexão, o jovem possa formar o seu juízo moral na medida em que ele vai estabelecendo as distinções morais necessárias. Na medida em que observa o menor ou o maior conteúdo moral das ações apresentadas, as decisões morais, das quais são oferecidos os exemplos, são possíveis (KANT, 2003b, p. 543; 566).

Na obra Crítica da razão prática (1788) Kant expõe, de modo sumário, o que, posteriormente, com a Metafísica dos costumes, amplia. Na sua Crítica diz:

\begin{abstract}
Não sei por que os educadores da juventude não fizeram já há tempo uso dessa propensão da razão de proceder com prazer ao exame mais sutil de questões práticas levantadas e por que, depois de terem tomado por base um catecismo puramente moral, não esquadrinharam as biografias de épocas antigas e modernas com o propósito de terem à mão exemplos para os deveres apresentados (KANT, 2003b, p. 543).
\end{abstract}

No entanto, devemos ressaltar que os bons exemplos extraídos da história não se tratam apenas de modelos a serem seguidos. A posição de Kant é que a história não deve servir exclusivamente de um modelo passível de comparações, pois se assim fosse, somente um modelo de comparação, não serviria para outra coisa senão para o desenvolvimento de uma inclinação qualquer, por exemplo, 
ódio, rancor, ira. A história não deve servir de modelo de comparação, mas de prova de que o prescrito pelo dever, todo o mandamento do dever-ser - tudo o que deve necessariamente ocorrer do ponto de vista moral - é factível, efetivo, realizável.

Os bons exemplos históricos, oferecidos à propensão da natureza humana de imitar, devem servir de auxílio à aceitação de máximas morais, um princípio em função do qual o sujeito quer viver e, posteriormente, com a formação do juízo moral, o móbil (e motivo) da ação será a própria ideia do dever-ser.

Nota-se que a razão de determinação da ação com valor moral não será a história ou o bom exemplo histórico, mas sim a própria ideia do dever.

Sobre o papel da história na formação moral do educando, eis o que nos aponta Kant na Crítica da razão prática:

\begin{abstract}
Conte-se a história de um homem honesto que se quer instar a aderir aos caluniadores de uma pessoa inocente e, além disso, carente de posses (como talvez Ana Bolena, acusada por Henrique VIII, da Inglaterra). Oferecem-se vantagens a ele, isto é, grandes presentes e um alto posto e ele as recusa [...] Começa-se então com ameaça de perdas. Entre esses caluniadores encontram-se seus melhores amigos, que lhe retiram sua amizade, parentes próximos que ameaçam - a ele (que não tem posse) - deserdá-lo e poderosos que em cada lugar e circunstância podem persegui-lo e melindrá-lo, um soberano que o ameaça com a perda da liberdade e da própria vida. Mas, para que a medida da adversidade seja completa e para deixa-o sentir também a dor que somente o coração moralmente bom pode sentir de maneira verdadeiramente íntima, represente-se a sua família ameaçada de extrema necessidade e penúria, implorando-Ihe a transigência; represente-se a ele mesmo, embora reto, contudo dotado de órgão de sentidos não empedernidos e insensíveis à compaixão e à necessidade própria, em um momento em que ele deseja jamais ter vivido o dia que o expôs a uma dor tão inexprimível, todavia permanecendo fiel, sem vacilar e duvidar, a seu propósito de honestidade (KANT, 2003b, p. 547, 549). Grifos acrescentados.
\end{abstract}

Segundo Kant, isto poderá causar aplauso e a aprovação do ouvinte, causar uma gradual admiração e "um vivo desejo de poder ser ele mesmo um tal homem (embora certamente não na sua circunstância)" (KANT, 2003b, p. 549), mas, a aprovação, a admiração e o esforço para assemelhar-se a esse caráter, dependerão, inteiramente, do princípio moral, o qual deve ser representado de modo puro e "como saltando diretamente aos olhos do ouvinte" (KANT, 2003b, p. 549), ou seja, afastando dos motivos da ação tudo o que os seres humanos 
podem desejar sensivelmente, por exemplo, a sua própria felicidade, glória ou bem-estar. Segundo Guyer (2006, p. 247), ao chamar uma pessoa de virtuosa, de acordo com filosofia prática kantiana, afirmamos a pureza de sua motivação.

De acordo com Kant, o princípio moral, que revela o valor moral da ação, terá mais força moral quanto mais pura, o que significa afastar toda e qualquer tendência, inclinação, impulso de apresentar a moralidade, o caráter, a virtude, valiosos em si e não porque trazem alguma espécie de compensação. Desse modo, acerca da força do bom exemplo - a técnica da educação para a moralidade - não se trata de meras comparações de um ser humano com o outro, mas de trazer à luz a ideia de humanidade, a ideia de tudo aquilo que é possível acontecer do ponto de vista moral.

Ainda, de acordo com o exposto na Crítica da razão prática, poderíamos pensar, a partir da segunda Crítica, bem como em outros exemplos oferecidos pelo filósofo na Fundamentação da metafísica dos costumes (KANT, 1980) nos quais a ideia do dever é evidenciada mediante dados históricos, que somente há valor moral nas ações em situações adversas, ou seja, situações com obstáculos diversos e limitações subjetivas, porém a posição de Kant é que as limitações e obstáculos subjetivos tornam ainda mais evidente a noção de dever, pois em vez de ocultarem o dever moral/prático, o faz brilhar com luz ainda mais clara, daí a razão da apresentação de casos (exemplos a partir da história) nos quais as limitações são numerosas, no entanto, o valor moral da ação não se resume aos casos de limitações e obstáculos. Vale observar aqui, também, que, conforme aponta Kant (1999, p. 64), os exemplos históricos são meios muito bons para o exercício do entendimento no que diz respeito ao julgamento moral.

Parte do objetivo da técnica sustentada por Kant para o ensino da moralidade, para a formação e o desenvolvimento moral do educando é, em primeiro lugar, encontrar uma representação tangível da ética, algo que possa ser visto, sentido, ouvido e imitado, o que representa a determinação da vontade por máximas aceitas, as quais, em seguida, com a formação do juízo moral, o educando adota - a adoção de uma máxima moral segundo a qual se quer viver.

A posição do filósofo é que o ser humano, ainda não formado, necessita da manifestação física da virtude com a qual ele possa se identificar e, com ela, aprender. O estudante necessita, no primeiro momento, se deixar levar por uma 
linha condutora que pode ocorrer por meio da história, dos bons exemplos retirados da história, para depois aperceber-se que a norma repousa somente na sua própria razão; isso na medida em que não se perde a noção do dever, enquanto o motivo da ação com valor moral, ao oferecer os exemplos:

[...] por respeito a seu dever e não por impulsos do coração [...] Esta é a única maneira de pensar que forma moralmente a alma, porque somente ela é capaz de proposições fundamentais firmes e rigorosamente determinadas" (KANT, 2003b, p. 299, grifo nosso).

Vale dizer que, segundo a concepção de moralidade de Kant, se há a preocupação com o valor moral da ação o ser humano não pode se deixar guiar por um "princípio", por uma determinação, uma razão ou motivo vacilante, por uma determinação que, causalmente ou acidentalmente, pode levar ao bem, mas que, em muitas situações, pode também acarretar em um grande mal.

\section{Considerações Finais}

O Método e a Técnica, expostos por Kant em sua Metafísica dos costumes, são as instruções da teoria, isto é, são meios que os professores podem empregar para o desenvolvimento moral de seus alunos, porém, a contrapartida prática, a realização/efetivação desses exercícios da teoria encerra-se no Ascetismo: no cultivo da moral, no cultivo da capacidade para a virtude. Afinal, com o método e a técnica é desenvolvida a ideia dos valores, é desenvolvido o juízo moral no educando, o como efetivar a moralidade/virtude, pois realizar ações éticas, propriamente ditas, na vida e vivências da natureza humana, requer o ascetismo, que pode ocorrer, segundo Kant, pelo exercício.

A "ginástica ética"2, ou seja, o exercício da moralidade, uma vez despertado o juízo moral ou a razão prática do educando, consiste na luta ou fortaleza moral contra as inclinações naturais que, em última instância, encerra-se em virtude. Nesse sentido, o cultivo da moralidade, segundo Kant (2004b, p. 136), torna a humanidade valorosa e alegre mediante a consciência de ter reconquistado a

2 Cf. Kant (2004b, p. 135). 
liberdade. O ânimo valoroso e o ânimo alegre são, de acordo com Kant, as consequências do cultivo da moralidade, as consequências do exercício da virtude.

Devemos observar que a ascensão moral na vida humana pode ocorrer, segundo Kant, pelo exercício da moralidade e, tal como o exercício físico fortalece a condição física/corporal, o exercício moral fortalecerá a condição moral da natureza humana.

Veja, o exercício moral ou "ginástica ética" não se resume apenas em adquirir ou perder um hábito, não se resume ao mero hábito de ações repetidas durante um longo tempo, afinal, para Kant (2004b, p. 130), um hábito "é o estabelecimento de uma inclinação persistente sem nenhuma máxima", a moralidade requer a adoção de máximas morais - o reconhecimento, a adoção de um princípio segundo o qual se quer viver. O que é habitual, a inclinação persistente, pode não determinar em todos os casos, justamente pela alteração e fragilidade que as novas seduções podem provocar.

Portanto:

[...] toda prática da moralização envolve a adoção de máximas que determinam o que queremos ser. A adoção de uma máxima pressupõe que o ser humano seja capaz de pensar por si mesmo e decidir o que ele quer fazer de si. Talvez possamos dizer que a educação consiste na passagem da inteira dependência de um ser humano, a criança, em relação a outro ser humano, o adulto, até a sua independência em relação a esse. Daí Kant ter como o objetivo da educação o incentivo à prática da autonomia e da autodeterminação (BUENO, 2012, p. 168).

Por meio das instruções teóricas, o meio experimental ou técnica da moral (o bom exemplo histórico), bem como a partir do cultivo da moralidade (o exercício moral, uma vez despertado a razão do educando para o conceito), enxergamos, em Kant, na obra Metafísica dos costumes, um caminho pelo qual é possível fazer com que o ser humano possa querer viver virtuosamente, eis o fundamento moral na vida moral.

O que é imprescindível, pois a ação com valor moral, conforme nos expõe Kant, requer essa adoção subjetiva (a adoção do sujeito da ação) do princípio prático objetivo, afinal, de nada valeria a objetividade de um princípio se o 
sujeito da ação não o quiser para si. Trata-se do querer (subjetivo) fazer o que deve (objetivo) ser feito do ponto de vista da moralidade, dos valores morais.

O método, a técnica, e o cultivo da moralidade, na formação ou desenvolvimento moral do educando, segundo o filósofo, podem ser eficazes na constituição desse querer, na adoção do princípio pelo próprio querer, para que o ser humano queira a sua ação enquanto moral, queira agir segundo o princípio da moralidade - por razões ou motivos morais - e realize, por fim, as suas ações ética no mundo, no real. A ação ética em sua vida e vivências.

A Metafísica dos costumes expõe um modo pelo qual se pode despertar na natureza humana, em particular no jovem, o interesse e o querer a prática da virtude, a possibilidade da adoção de uma espécie de regra de vida, um princípio, que o agente se dá e toma para si. Assim sendo, o querer ou o agir do sujeito da ação serão movidos, necessariamente, em função dessa adoção.

Finalizando, apontamos que a pedagogia kantiana, ademais, nos oferece:

i) as instruções teóricas para a formação moral, expressas no método erotemático de ensino (catequético e dialógico);

ii) as instruções teóricas oferecidas, mediante a exposição da técnica ou o meio experimental, para a moralidade (o bom exemplo histórico);

iii) a contrapartida prática, a ginástica ética, uma vez formado o juízo ou razão do educando.

Eis o que Kant buscou com a sua pedagogia: oferecer um projeto sistemático de uma teoria da educação pela qual pudesse desenvolver, no ser humano, o que de fato convém à sua natureza, para que este pudesse atingir o seu verdadeiro fim, a sua verdadeira destinação - a sua Humanidade.

Desse modo, mesmo que haja obstáculos na realização do seu projeto educacional, Kant sustenta que não é em vão oferecer um ideal de educação a ser perseguido pelo ser humano para o seu aperfeiçoamento, sua futura felicidade e perfeição. De acordo com o filósofo, a Ideia não deve ser considerada como quimérica, ou belo sonho, caso haja obstáculos em sua realização. Conforme explica Santos, a educação kantiana, mesmo tratando-se um projeto (pensamento, teoria ou conceito), não se trata de uma utopia, antes, 
ainda, conforme outra definição kantiana, como focus imaginarius. Por meio da idéia de educação, a Pedagogia pode regular-se na experiência, o que permite que ela não seja reduzida a puro empirismo (SANTOS, 2004, p, 54).

No que diz respeito ao seu projeto de educação, Kant (1999, p. 21) especifica que toda a arte da educação, do mesmo modo o seu progresso, é ou i) mecânica - ordenada sem plano e conforme as circunstâncias, ou ii) raciocinada - pensada, refletida, planejada. Toda educação meramente mecânica contém muito erros e lacunas por não obedecer a plano algum. A educação, caso queira desenvolver a natureza humana de tal modo que o ser humano possa atingir a sua humanidade, deve ser raciocinada, senão, segundo Kant, nada se pode esperar da educação. Acerca da boa educação a posição do filósofo é que "é preciso colocar a ciência no lugar do mecanicismo" (KANT, 1999, p. 22), pois de outro modo, a educação jamais se tornará um esforço coerente e "uma geração poderia destruir tudo o que uma outra anterior tivesse edificado" (KANT, 1999, p. 22).

Enxergamos a pedagogia kantiana envolvendo o desenvolvimento e a adoção de princípios determinadores do que queremos ser, afinal, a adoção de um princípio pressupõe que o ser humano seja capaz de pensar por si mesmo e decidir o que quer fazer de si.

Após nossa exposição, queremos deixar algumas questões para reflexão: a pedagogia de Kant pode ser oportuna às questões atuais acerca da educação e do desenvolvimento moral do educando? Podemos pensar na aposta de uma formação educacional que mostra a possibilidade e a efetividade da ação ética, propondo princípios e valores morais como exercício? De que modo o pensamento ajuíza (ou pode ajuizar) a educação hoje? O pensamento pode (ou deve) ser considerado na realidade? Oferecemos, a partir da Pedagogia de Kant, a expressão conceitual, a teoria, a ideia, em resumo, o projeto de educação ou a alternativa teórica. Nesse sentido, podemos, enquanto educadores, nos valer dos arquétipos que podem orientar e promover uma ação educativa absoluta?

\section{Referências}


BRASIL. Decreto-Lei no. 869, de 12 de setembro de 1969. Dispõe sobre a inclusão da Educação Moral e Cívica como disciplina obrigatória, nas escolas de todos os graus e modalidades, dos sistemas de ensino no País, e dá outras providências. Disponível em:

<http://www2.camara.leg.br/legin/fed/declei/1960-1969/decreto-lei-869-12setembro-1969-375468-publicacaooriginal-1-pe.html>. Acesso em: 20 out. 2017.

BUENO, V. C. A. Kant e a tarefa da educação. In. OLIVEIRA, P. E. (Org.) Filosofia e educação: aproximações e convergências. Curitiba: Círculo de Estudos Bandeirantes, 2012.

GUYER, P. Kant. Londres: Routledge, 2006.

KANT, I. A metafísica dos costumes. Bauru: Edipro, 2003a.

KANT, I. Crítica da razão prática. São Paulo: Martins Fontes, 2003b.

KANT, I. Crítica da razão pura. São Paulo: Abril Cultural, 1983.

KANT, I. Crítica do juízo. Rio de Janeiro: Forense Universitária, 1993.

KANT, I. Fundamentação da metafísica dos costumes. São Paulo: Abril Cultural, 1980.

KANT, I. Metafísica dos costumes. Parte I: princípios metafísicos da doutrina do direito. Lisboa: Ed. 70, 2004a.

KANT, I. Metafísica dos costumes. Parte II: princípios metafísicos da doutrina da virtude. Lisboa: Ed. 70, 2004b.

KANT, I. Sobre a pedagogia. Piracicaba: Unimep, 1999.

OLIVEIRA, M. N. A educação na ética kantiana. Educação e Pesquisa, São Paulo, v. 30, n. 3, p. 447-460, set./dez. 2004.

SANTOS, R. Kant e a exigência de uma ciência da educação. Educação em Revista, Belo Horizonte, n. 5, p. 49-62, 2004. 